\title{
Las estrategias de marketing en la planificación y gestión del patrimonio cultural militar: estudio de caso
}

\author{
María Teresa Fernández Alles* \\ Universidad de Cádiz (España)
}

\begin{abstract}
Resumen: El Ministerio de Defensa del Gobierno de España custodia un patrimonio cultural de gran riqueza, considerado uno de los atractivos más relevantes de la oferta turística y cultural española. La gestión que, bajo la denominación de Difusión de la Cultura de Defensa, realiza el Ministerio de Defensa para la puesta en valor de este patrimonio, ha contribuido considerablemente tanto a su difusión en la sociedad como a la dinamización de las economías locales, impulsando a su vez el desarrollo del sector turístico. Esta investigación pretende estudiar la gestión que, bajo el enfoque del marketing, realiza el Ministerio de Defensa con el doble propósito de hacer difusión del mismo en el conjunto poblacional, y especialmente en la sociedad civil, y de conservar los bienes que lo integran. Para ello se ha acudido al método del caso como metodología de la investigación, siendo el caso objeto de estudio el Museo Naval situado en la localidad española de San Fernando (Cádiz).
\end{abstract}

Palabras Clave: Patrimonio cultural; Museos; Gestión; Turismo cultural; Cultura de defensa.

Marketing strategies in the planning and management of military cultural heritage: a case study

Abstract: The Ministry of Defense of the Government of Spain possesses a large and rich store of cultural heritage of great wealth, considered highly relevant as a cultural tourism attraction. Heritage Management, called Promotion of the Culture of Defence is carried out by the Ministry of Defense itself and is designed to give value-added to this heriatge making it available toward the revitalisation of local economies through development in the area of tourism. This research aims to study the marketing perspective of the heritage management, carried out by the Ministry of Defence to the double purpose of creating general public awareness through heritage promotion while preserving said legacy collections. This then is a case study of the Naval Museum in the Spanish town of San Fernando (Cádiz).

Keywords: Cultural heritage; Museums; Management; Cultural tourism; Culture of defence.

\section{Introducción}

El turismo cultural, modalidad turística que abarca todos aquellos desplazamientos que se realizan "principalmente con el motivo de conocer manifestaciones artísticas, culturales, arqueológicas, monumentales y, en general, cualquier manifestación humana que ayude al enriquecimiento cultural" (Milio y Cabo, 2000, 124), está cobrando un protagonismo creciente en el panorama turístico mundial, lo que queda reflejado en las cifras registradas en el sector. Concretamente, en España, las estadísticas relativas a los viajes realizados por motivos culturales, tanto por los residentes en España como por los turistas internacionales, ponen de manifiesto la relevancia de la cultura para el sector turístico, por cuanto, según los últimos datos publicados por el Ministerio de Educación, Cultura y Deporte (2017), correspondiente al año 2016, el 17,8\% del total de los viajes realizados por los residentes en España por ocio, recreo o vacaciones fueron por motivos culturales, cifrándose en 14,3 millones los viajes registrados.

En cuanto a los turistas internacionales, se registraron un total de 7,2 millones los viajeros extranjeros que acudieron a España por el mismo motivo, representando el 12,4\% del total de los viajes realizados

Universidad de Cádiz, España; E-mail: teresa.alles@uca.es 
por estos por ocio, recreo o vacaciones. La evolución de los viajes realizados tanto por los residentes en España como por los turistas internacionales por motivos culturales se muestra en la gráfica 1.

\section{Gráfica 1: Viajes de residentes en España y turistas internacionales realizados por motivos culturales (en millones). Periodo 2005-2016.}

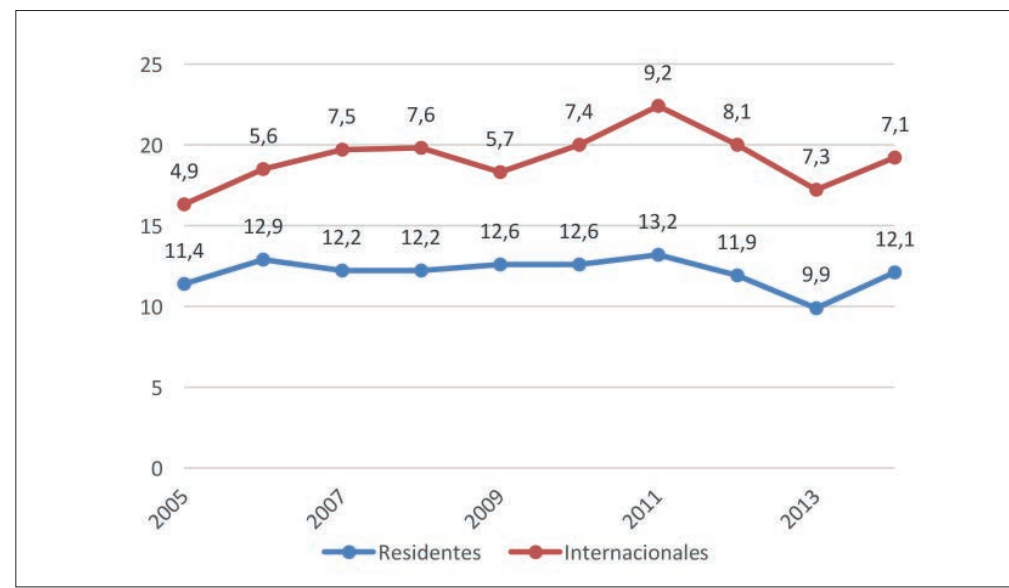

Fuente: Ministerio de Educación, Cultura y Deporte (2016). Elaboración propia.

El desarrollo de esta modalidad turística, el turismo cultural, en un destino turístico se sustenta en la riqueza, conservación y difusión de su patrimonio cultural. Según Fernández y Ramos (2005), este patrimonio estaría constituido "por todos aquellos elementos y manifestaciones tangibles e intangibles producidos por las sociedades resultado de un proceso histórico en el que la reproducción de las ideas y el material se constituyen en factores que identifican y diferencian a ese país o región". Por otra parte, la legislación vigente en España, la Ley 16/1985, de 25 de junio, de Patrimonio Histórico Español, integra dentro de este patrimonio "los inmuebles y objetos muebles de interés artístico, histórico, paleontológico, arqueológico, etnográfico, científico o técnico...el patrimonio documental y bibliográfico, los yacimientos y zonas arqueológicas, así como los sitios naturales, jardines y parques, que tengan valor artístico, histórico y antropológico. Asimismo, forman parte del Patrimonio Histórico Español los bienes que integren el Patrimonio Cultural Inmaterial, de conformidad con lo que establezca su legislación especial" (artículo $1^{\circ}$ del Título Preliminar).

Atendiendo a su titularidad, cabe distinguir entre el patrimonio de titularidad pública, de titularidad privada y de titularidad mixta. El primer grupo se compone de los bienes, muebles e inmuebles, materiales e inmateriales, que pertenecen a la Administración General del Estado, a la Autonómica o bien a la Administración Local, formando parte de los primeros aquellos cuya titularidad y gestión corresponden al Ministerio de Defensa.

El patrimonio gestionado por este ministerio integra una destacada oferta cultural (archivos, bibliotecas, museos, edificios, etc.), cuya difusión y acercamiento a la sociedad están contribuyendo de manera relevante a impulsar, tanto el desarrollo turístico y económico de las localidades en las que se encuentra ubicados, como la puesta en valor de dicho patrimonio. Todo ello ha sido posible gracias a las actuaciones llevadas a cabo por el Ministerio de Defensa enmarcadas en la denominada Difusión de la Cultura de Defensa.

La Cultura de Defensa hace referencia al "conjunto de conocimientos que permite a las personas desarrollar juicios u opiniones sobre los instrumentos con que el Estado protege a los ciudadanos de determinados peligros, siendo las Fuerzas Armadas uno de los instrumentos más importantes" (Ministerio de Defensa, 2018). El desarrollo de la misma tiene como finalidad "que la sociedad española conozca, valore y se identifique con la historia y con el esfuerzo solidario y efectivo mediante el que las Fuerzas Armadas salvaguardan los intereses nacionales" (Ministerio de Defensa, 2018). Con ello, se pone de manifiesto que uno de los propósitos fundamentales de la Difusión de la Cultura de Defensa es la apertura a la sociedad civil. 
Como afirma el General Alejandre (2017), Jefe de Estado Mayor de Defensa (JEMAD), "la cultura y la conciencia de seguridad y defensa son conceptos de índole nacional y no responsabilidad exclusiva del Ministerio de Defensa", destacando la importancia no sólo de que las Fuerzas Armadas se acerquen a la sociedad civil, sino también que la propia sociedad civil se acerque a ese conocimiento y compromiso de seguridad nacional.

Para lograr este acercamiento y apertura del patrimonio cultural militar, el Ministerio de Defensa ha implantado una nueva forma de gestión cuyo éxito ha quedado plasmado en casos tan destacados como la Colección Museográfica de la Guardia Real, el Museo del Alcázar de Segovia o el Museo Histórico Militar de Burgos.

A nivel académico, no existen antecedentes de trabajos en los que se analicen o ponga de manifiesto esta nueva forma de gestión de los bienes que integran el patrimonio cultural de Defensa. Por ello, consideramos que este trabajo puede suponer una aportación importante en este campo de la investigación.

Dada la amplitud del patrimonio dependiente del Ministerio de Defensa, esta investigación se centrará, utilizando como metodología el método del caso, en el análisis de un caso concreto al objeto de alcanzar el objetivo fundamental de la misma como es dar a conocer esta nueva forma de gestionar el patrimonio cultural por parte del Ministerio de Defensa.

El recurso del patrimonio cultural militar español seleccionado como caso de estudio será el Museo Naval ubicado en la localidad española de San Fernando, en la provincia de Cádiz (España). La elección de este museo obedece a las siguientes razones: el haber sido la primera sede del Museo Naval, ubicado actualmente en la capital de España, Madrid (De Leste, 2018); su destacada contribución a la difusión de la Cultura de Defensa; su importancia estratégica en la oferta cultural de la zona geográfica en la que se encuentra ubicado; y el éxito de público alcanzado por este museo en los últimos años.

En líneas generales, lo que se pretende con el estudio de este caso es conocer la política museística que está llevando a cabo el Ministerio de Defensa, no sólo en el cumplimiento de las verdaderas funciones para las que fueron creados (conservación, investigación, difusión y función social), sino, además, en su labor de difusión y comunicación.

\section{La gestión de los museos bajo el enfoque del marketing}

Uno de los componentes clave del patrimonio cultural en España, y particularmente, del patrimonio cultural militar, son los museos. Estos pueden ser definidos, según la American Association of Musseums (AAM), como "un centro organizado como institución pública o privada no lucrativa, cuya existencia se justifica mediante unos objetivos esencialmente estéticos o educativos" (Kotler y Kotler, 2008, 32). Otra de las definiciones existentes en torno a este importante bien cultural es la que recoge en el artículo 59.3 de la Ley 16/1985, de 25 de junio, del Patrimonio Histórico Español, según la cual "son museos las instituciones de carácter permanente que adquieren, conservan, investigan, comunican y exhiben para fines de estudio, educación y contemplación conjuntos y colecciones de valor histórico, artístico, científico y técnico o de cualquier otra naturaleza cultural" (art. 1 del Reglamento 620/1987, de 10 de abril, por el que se aprueba el Reglamento de Museos de Titularidad Estatal y del Sistema Español de Museos).

Los museos constituyen uno de los atractivos más importantes de la oferta turístico-cultural española, habiendo contribuido de manera relevante a posicionar el turismo cultural como una de las modalidades turísticas más importantes en España, jugando, a su vez, un destacado papel en la desestacionalización de la demanda turística. Particularmente, según las últimas estadísticas publicadas, la visita a museos o exposiciones fue una actividad cultural realizada por el 33,2\% de la población española en el periodo 2014-2015 (Encuesta de Hábitos y Prácticas Culturales en España, Ministerio de Educación, Cultura y Deporte, 2016a).

En 2015, se contabilizaron un total de 1.522 museos y colecciones dentro de la oferta museística española (Ministerio de Educación, Cultura y Deporte, 2016a), de los cuales el 70,2\% son de titularidad pública, siendo el 27,9\% de titularidad privada y el 1,9\% mixta. Entre los primeros, de titularidad pública, destacan los museos de la Administración Local (46,7\%), seguidos de los de la Administración General del Estado (11,6\%) y la Autonómica (9,5\%). Dentro de los primeros se encuentran aquellos cuya titularidad y gestión corresponden al Ministerio de Defensa, cifrándose en 22 los museos y 25 las colecciones museográficas (Ministerio de Educación, Cultura y Deporte, 2016a). El órgano responsable de la coordinación de los mismos es la Subdirección General de Publicaciones y Patrimonio Cultural del Ministerio de Defensa (Ministerio de Defensa, 2016a). 
Existen diversas tipologías dentro de los museos gestionados por el Ministerio de Defensa: Museos Nacionales, Museos Históricos Militares del Ejército de Tierra y museos filiales del Museo Naval. Todos ellos albergan un total de 78.633 fondos museísticos que se agrupan en la Red de Museos de Defensa (RMD). Esta red se creó en virtud del Real Decreto 1305/2009, de 31 de julio, por la que se crea la Red de Museos de España, siendo preciso tener en consideración, además, la Orden DEF/2532/2015, de 18 de noviembre, por la que se crea la Red de Museos de Defensa y se definen los procedimientos para la gestión de los bienes muebles del Patrimonio Histórico Español adscritos al Ministerio de Defensa. El contenido de esta orden ministerial se ajusta a lo dispuesto en la Ley 16/1985, de 25 de junio, del Patrimonio Histórico Español; en el Real Decreto 111/1986, de 10 de enero, de desarrollo parcial de la Ley 16/1985, de 25 de junio, del Patrimonio Histórico Español; y en el Real Decreto 620/1987, de 10 de abril, por el que se aprueba el Reglamento de Museos de Titularidad Estatal y del Sistema Español de Museos.

Las Estadísticas de Museos y Colecciones Museográficas $(2016 \mathrm{~b})^{1}$ estimaron que las 1.522 instituciones museísticas investigadas recibieron 58.418 .342 visitantes a lo largo de 2014, siendo la media de visitantes por museo de 39.795. Estos museos han experimentado un notable crecimiento en el número de visitantes en los últimos años, cobrando especial protagonismo museos reconocidos internacionalmente como el Museo del Prado en Madrid o el Museo Guggenheim en Bilbao. La evolución del número de visitantes estimados en los museos y colecciones museográficas en España en el periodo 2006-2014 muestra una tendencia creciente tal y como se observa en la gráfica 2.

\section{Gráfica 2. Evolución del número de visitantes estimados a Museos y Colecciones Museográficas en España (en miles) (2006-2014).}

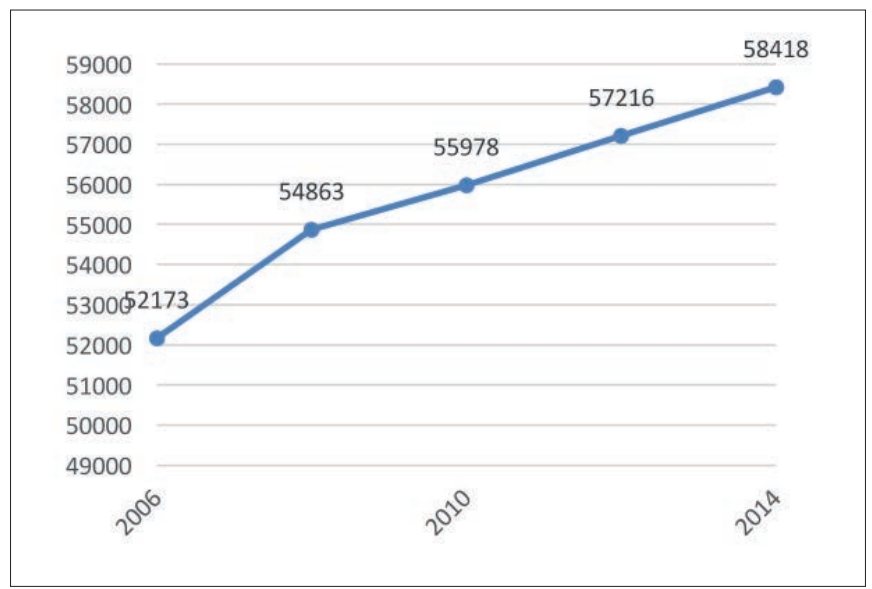

Fuente: Ministerio de Educación, Cultura y Deporte (2016b). Elaboración propia.

$\mathrm{Al}$ auge del turismo cultural en España no sólo ha contribuido la gran riqueza de su patrimonio cultural, sino también las acciones de comunicación y promoción llevadas a cabo por las diversas instituciones, tanto públicas como privadas.

Como afirma Martos (2016), la promoción del producto cultural facilita la consecución de una serie de objetivos entre los que cabe destacar:

a) Conseguir notoriedad en el mercado, dando a conocer el producto cultural.

b) Crear o modificar la imagen del producto cultural.

c) Recordar a los usuarios potenciales la existencia del producto cultural.

d) Mejorar el posicionamiento del recurso cultural.

e) Despertar el interés de un segmento de mercado concreto.

Bajo el enfoque actual del marketing, se considera necesario que la gestión moderna de los museos conjugue la utilización de técnicas de marketing, al objeto de atraer un mayor número de visitantes y turistas, con la preservación de los bienes. De ahí que se considere fundamental la elaboración de 
estrategias de marketing para aprovechar la oportunidad que supone para el turismo la difusión de la cultura.

Este enfoque se corresponde con una nueva forma de gestionar los museos por parte del Ministerio de Defensa, enmarcada en la denominada Difusión de la Cultura de Defensa, la cual puede tener una doble acepción (Fernández y Barbeito, 2005:69-70): la primera, la cual hace referencia "al conocimiento objetivo que la población dispone, o debiera disponer, sobre los asuntos relacionados con la defensa, tanto sobre la organización militar y las misiones de las Fuerzas Armadas, como sobre las políticas de defensa o la naturaleza y dinámica de los conflictos bélicos", y la segunda, que "alude al conjunto de prácticas valores, creencias, afectos y símbolos que la población mantiene o pueda mantener respecto a la defensa". Teniendo en cuenta estas consideraciones, la Cultura de Defensa lo que persigue es influir en los conocimientos y actitudes de los visitantes, constituyendo los museos un elemento clave para comunicar estos conocimientos e influir en las actitudes de manera positiva hacia lo que constituye la defensa nacional.

Bajo esta óptica, las funciones de los museos militares no se van a limitar a la colección y conservación del patrimonio que atesoran, sino que deben realizar una importante labor de comunicación que logre atraer a toda la población, no sólo a los militares interesados por este tipo de museos.

Como afirma González-Pola (2018), una de las misiones fundamentales de los museos militares debe ser acercar la Defensa a la sociedad civil, para lo cual es necesario que los museos se constituyan en espacios de aprendizaje que permitan conocer y comprender la historia del país. Es por ello que las políticas de comunicación de los museos militares deban ir encaminadas a dar a conocer su apertura a toda la población, creando museos accesibles que ofrezcan experiencias únicas y atractivas sobre todo a la población civil.

El primer Plan Director de Cultura de Defensa se aprobó en 2002, estando en proceso de elaboración la creación de un nuevo plan que contemple los cambios acaecidos en el entorno, así como la actualización de los enfoques y mecanismos de seguimiento establecidos en el anterior plan. Pues bien, desde la aprobación de este primer Plan Director, ha habido un cambio considerable en la forma de gestionar los museos, habiéndose realizado en los últimos años un verdadero esfuerzo por parte del Ministerio de Defensa por poner su patrimonio histórico y cultural a disposición de la ciudadanía. Tanto es así que, según los últimos datos proporcionados por el Ministerio de Defensa (2018), se han registrado en torno a 1.700.000 visitas en los museos y colecciones museográficas que gestiona.

Prueba de esta tendencia por acercar los museos a la sociedad es la participación del Ministerio de Defensa en el Año Europeo del Patrimonio Cultural en 2018, cuyo propósito es animar a todas las personas a descubrir y explorar el patrimonio cultural europeo, formando parte de las celebraciones que se están llevando a cabo en torno a la riqueza y la diversidad del patrimonio que atesoran las ciudades europeas.

\section{Metodologia de investigación y caso de estudio}

\subsection{Metodologia}

La presente investigación pretende analizar la gestión que el Ministerio de Defensa lleva a cabo en uno de los recursos más importantes del patrimonio cultural, los museos, desde el punto de vista del marketing. Este importante recurso patrimonial constituye uno de los principales atractivos de la oferta turística española, interviniendo en su gestión distintos agentes y factores, económicos, sociales y culturales, por lo que se considera el método del caso la estrategia de investigación más idónea para realizar esta investigación. Esta metodología permite dar respuesta a interrogantes del tipo ¿cómo? y ¿por qué? (Yin, 2009), así como ahondar en la comprensión del fenómeno, aportando una visión holística (Gummenson, 1991). De igual forma, al existir pocos trabajos que analicen la sostenibilidad en el patrimonio cultural, en general, y en los museos, en particular, y, concretamente, en los museos gestionados por el Ministerio de Defensa, este trabajo constituye una aportación relevante al campo objeto de estudio.

Una vez realizada la revisión de la literatura, se ha procedido a fundamentar las cuestiones de investigación y a seleccionar la unidad de análisis, para realizar el adecuado planteamiento de la metodología a emplear y del contenido de las entrevistas y de la información requerida. Tras consultar el universo de museos existentes en España, se decidió centrar la investigación en los museos de titularidad pública y, concretamente, en aquellos gestionados por el Ministerio de Defensa. Dada la inexistencia de trabajos académicos en este ámbito, se decidió utilizar como metodología de investigación el método 
del caso, ya que así se podría conocer al completo todo lo relativo a la gestión turística de los museos desde la óptica del marketing.

Tras la fundamentación teórica y metodológica de este trabajo, se pasó a la fase de obtención de la información primaria. Concretamente, se solicitó información referente al número de visitantes a los museos, la evolución longitudinal de dicho número, así como a las políticas de marketing llevadas a cabo. Así, se ha llevado a cabo una investigación de carácter exploratorio, basada en la búsqueda documental, recopilando información relativa a la gestión turística del museo analizado y de las políticas de marketing implementadas para la difusión de su patrimonio.

Una vez obtenida la información, ésta fue clasificada y sintetizada para su posterior análisis, permitiendo extraer conclusiones generales aplicables a otros museos, compartiendo las características esenciales. En la tabla 1 se recoge la información sintetizada del proceso de investigación llevado a cabo basado en la metodología del caso.

\section{Tabla 1: Metodología de la investigación.}

\begin{tabular}{|c|c|}
\hline Propósito de la investigación & $\begin{array}{l}\text { Comprobar empíricamente como se lleva a cabo la gestión turística de } \\
\text { los museos en un caso real para analizar las estrategias y acciones que } \\
\text { se emprenden para la difusión de la cultura, así como las medidas que } \\
\text { se llevan a cabo para incrementar la notoriedad y el flujo de visitantes. }\end{array}$ \\
\hline Metodología de investigación & $\begin{array}{l}\text { Estudio de caso contemporáneo singular de carácter holístico (unidad } \\
\text { de análisis simple). Estudio exploratorio, descriptivo y explicativo. }\end{array}$ \\
\hline Unidad de análisis & Museos en España. \\
\hline Ámbito geográfico & España \\
\hline Universo & $\begin{array}{l}\text { Museos españoles de titularidad pública gestionados por el Ministerio } \\
\text { de Defensa. Concretamente, los museos filiales del Museo Naval de } \\
\text { Madrid. }\end{array}$ \\
\hline Muestra & Museo Naval de San Fernando (Cádiz). \\
\hline Tipo de muestra & $\begin{array}{l}\text { Muestra lógica y teórica (capacidad de generalización analítica del } \\
\text { fenómeno estudiado), no de forma aleatoria (muestreo y generalización } \\
\text { estadística). }\end{array}$ \\
\hline Métodos de recogida de evidencia & Revisión documental. \\
\hline Fuentes de información & $\begin{array}{l}\text { Interna: documentación aportada por la gerencia del museo, contenido } \\
\text { de las entrevistas y contexto físico real. } \\
\text { Externa: publicaciones especializadas, estadísticas e información } \\
\text { publicada en las páginas web del Ministerio de Defensa. }\end{array}$ \\
\hline Informadores clave & $\begin{array}{l}\text { El director del museo, la directora técnica del museo y la Subdirección } \\
\text { General de Publicaciones y Patrimonio Cultural del Ministerio de } \\
\text { Defensa. }\end{array}$ \\
\hline $\begin{array}{l}\text { Métodos de análisis de la } \\
\text { evidencia }\end{array}$ & $\begin{array}{l}\text { Fundamentalmente de tipo cualitativo: } \\
\text { - Identificación y evolución de la importancia del turismo cultural. } \\
\text { - Relevancia de los museos en la oferta turístico-cultural. } \\
\text { - Explicación de las herramientas de marketing utilizadas tanto por la } \\
\text { Subdirección General de Publicaciones y Patrimonio Cultural como } \\
\text { por el museo analizado para dar a conocer su patrimonio. }\end{array}$ \\
\hline Enfoque científico & $\begin{array}{l}\text { Inducción analítica a través de la lógica de la réplica (generalización } \\
\text { analítica). } \\
\text { Procesos deductivos en la medida que se parte de proposiciones teóricas } \\
\text { a través de la revisión de la literatura. }\end{array}$ \\
\hline $\begin{array}{l}\text { Evaluación del rigor y calidad } \\
\text { científica }\end{array}$ & $\begin{array}{l}\text { - Análisis de la validez de constructo, interna y externa. } \\
\text { - Fiabilidad. } \\
\text { - Consistencia (teórico-interpretativa y contextual). }\end{array}$ \\
\hline Fecha de realización & $2017-2018$ \\
\hline
\end{tabular}

Fuente: Elaboración propia a partir de Villareal y Landeta (2010). 


\subsection{Caso de estudio}

De los 1.522 museos y colecciones museísticas registrados en España, 47 son gestionados por el Ministerio de Defensa, contando con 22 museos de titularidad estatal y 25 colecciones museográficas. Particularmente, los museos que gestiona el Ministerio de Defensa están integrados por 4 Museos Nacionales, 11 Museos Históricos Militares del Ejército de Tierra y 7 museos filiales del Museo Naval, los cuales reúnen un extenso patrimonio histórico y artístico de carácter militar, considerado como uno de los más importantes del mundo (Tabla 2).

Tabla 2: Museos gestionados por el Ministerio de Defensa de España.

\begin{tabular}{|l|}
\hline \multicolumn{1}{|c|}{ Museos Militares } \\
\hline \multicolumn{1}{|c|}{ Nacionales } \\
\hline - Museo del Ejército, en Toledo. \\
- Museo Naval, en Madrid. \\
- Museo de Aeronáutica y Astronáutica, en Cuatro Vientos (Madrid). \\
- Museo del Alcázar de Segovia, con titularidad estatal y gestión compartida. \\
\hline \multicolumn{1}{c|}{ Histórico Militares del Ejército de Tierra } \\
\hline - A Coruña. \\
- Burgos. \\
- Santa Cruz de Tenerife. \\
- Cartagena (Murcia). \\
- Ceuta. \\
- Figueras (Girona) \\
- Melilla. \\
- Porto Pi (Palma de Mallorca). \\
- Sevilla \\
- Valencia \\
\hline \\
\hline - Cartagena (Murcia). \\
- A Ferrol (A Coruña). \\
- Las Palmas de Gran Canaria. \\
- San Fernando (Cádiz). \\
- Museo Marítimo de la 'Torre del Oro' en Sevilla \\
- Archivo Museo 'Don Álvaro de Bazán', Viso del Marqués (Ciudad Real). \\
- Panteón de Marinos Ilustres, en San Fernando (Cádiz). \\
\hline
\end{tabular}

Fuente: Ministerio de Defensa (2016b). Elaboración propia.

Entre los museos filiales del Museo Naval de Madrid se encuentra el Museo Naval de San Fernando (Cádiz), en el cual se centrará la actual investigación. Las razones que justifican la elección de este museo como caso de estudio se debe a las siguientes razones: su destacada contribución a la difusión de la Cultura de Defensa; su importancia estratégica en la oferta cultural de la zona geográfica en la que se encuentra ubicado; y el éxito de público alcanzado por este museo en los últimos años.

Además, cabe destacar el hecho de que en el Museo Naval de San Fernando se sitúan los orígenes del actual Museo Naval de Madrid (De Leste, 2018), cuya creación se remonta a 1792 a iniciativa de don Antonio Valdés, designado Secretario de Marina e Indias por el rey Carlos IV. Su ubicación originaria contaba con una biblioteca, así como con una amplia exposición de instrumentos náuticos, modelos de barcos, armas, equipos, máquinas y otros objetos (De Leste, 2018).

El cese de Valdés paralizó el proyecto, el cual fue retomado medio siglo después, en 1842. Un año más tarde, el 19 de noviembre de 1843, S.M. la reina Isabel II inauguraría el Museo Naval en su primera sede en la capital española, situado en el Palacio o Casa de los Consejos ubicado en la calle Mayor (De Leste, 2018). 


\section{La gestión de marketing del museo naval de san fernando}

Las estrategias de marketing llevadas a cabo en el Museo Naval de San Fernando han ido encaminadas a la consecución de tres objetivos claros: incrementar el número de visitantes al museo, aumentar la visibilidad y notoriedad del museo y atraer nuevos públicos, tratando de lograr un posicionamiento definido: "ser un museo actual y especializado en el ámbito naval con un mayor reconocimiento en el mercado turístico" y "difundir la cultura de defensa" en la sociedad civil.

La gestión realizada para la puesta en valor de este importante recurso cultural y turístico, tanto desde el Ministerio de Defensa, el Órgano de Historia y Cultura Naval, la Fundación Museo Naval y el propio museo, ha contribuido a dar una mayor apertura del mismo hacia la sociedad en su conjunto. Esto ha repercutido positivamente en la dinamización de la economía local, impulsando el desarrollo del turismo cultural en la provincia, lo que se ha compatibilizado con la implantación de programas de conservación. Todo ello justifica la idoneidad de analizar la gestión realizada al objeto de que sirva de modelo para otros recursos patrimoniales.

Las estrategias funcionales llevadas a cabo en el museo se han centrado en las principales variables de marketing, destacando en primer lugar, las estrategias de productos, es decir, las centradas en el museo como producto. Con un producto claramente diferenciado, formando parte del conjunto de edificios arquitectónicos de la Armada, junto con el Panteón de Marinos Ilustres y el Real Instituto y Observatorio de la Armada, no existiendo una competencia directa en la zona con un producto de similares características, las estrategias de productos llevadas a cabo han sido diversas. En primer lugar, cabe resaltar la estrategia destinada a "acercar el museo a la ciudadanía", destacando entre sus actuaciones el cambio de ubicación del museo al centro de la ciudad.

Desde su fundación en marzo de 1992, el museo se hallaba situado en el primitivo edificio de la Intendencia y Colegio Naval, hoy Escuela de Suboficiales de la Armada, en la Real Población de San Carlos. Se trataba de un edificio construido en 1798 y de estilo neoclásico que contenía 19 salas de exposición en las que se exhibían barcos de distintas épocas, instrumentos náuticos, retratos o uniformes y condecoraciones, entre otros (Ministerio de Defensa, 2011). Al objeto de lograr un incremento en el número de visitantes al museo, difundiendo así su riqueza expositiva, se llevó a cabo un cambio de sede, ubicándose desde el 8 de julio de 2016, día de su inauguración, en el rehabilitado edificio histórico de la antigua Capitanía General de Marina de San Fernando. La nueva ubicación del museo en pleno centro histórico de la ciudad, lo han convertido en uno de los principales atractivos turísticos de la ciudad, teniendo un impacto directo en la afluencia de visitantes al mismo. Este cambio de ubicación quedaría englobado dentro de la estrategia de producto destinada a acercar el museo a la ciudadanía.

Otra de las actuaciones llevadas a cabo dentro de la estrategia de producto destinada a "acercar el museo a la ciudadanía", ha sido el desarrollo de un museo para todos, llevándose a cabo numerosas medidas de accesibilidad teniendo en cuentas las peculiaridades de los distintos tipos de discapacidad, no sólo la motora. Así, se ha diseñado un museo accesible para las personas con discapacidad, en el que las salas, los pasillos, la recepción, los aseos y los accesos a las distintas dependencias carecen de barreras que impidan que las personas con discapacidad puedan disfrutar del mismo en las mismas condiciones que el resto de la población.

Además, se han ampliado los idiomas en los que se pueden realizar las visitas, pudiéndose hacer tanto en castellano, como en inglés y en francés.

Otras de las estrategias llevadas a cabo ha sido la "mejora de la oferta de servicios", para lo cual se han llevado a cabo una serie de actuaciones, entre las que cabe incluir, en primer lugar, la ampliación del material expositivo, contando con un mayor número de bienes culturales en exposición. Particularmente, se ha procedido al traslado de algunos fondos desde el Museo Naval de Madrid, pudiendo resaltar el caso de la cabeza del mascarón del "Juan Sebastián Elcano". Se trata de una reproducción de una fragata del siglo XVIII que perteneció a Joaquín Sorolla. Asimismo, se llevan a cabo donaciones al museo, aprobadas por el Ministerio de Cultura, pudiendo citarse entre ellas los cuadros al óleo donados por la familia Padilla.

En segundo lugar, se ha realizado la ampliación y mejora del espacio expositivo (Imagen 1). En su ubicación actual, el Museo Naval de San Fernando está dividido en 18 áreas temáticas distribuidas en tres plantas. En las plantas 0 y 1 de Capitanía se encuentran las siguientes áreas temáticas:

1) Orígenes y fundación del museo.

2) El departamento marítimo de Cádiz (1717-1800).

3) Construccion naval en el siglo XVIII.

4) Batalla de trafalgar. 
5) El sitio de cádiz (1810-1812).

6) La vuelta al mundo de la fragata blindada numancia.

7) Cuba y Filipinas-1898-.

8) Formación naval y militar de los marinos españoles.

9) Expediciones marítimas españolas.

10) Vexilología naval.

11) Modelismo naval.

12) Artillería naval.

13) Sanidad naval militar.

14) La infantería de marina.

15) El arma submarina.

16) La armada contemporánea.

La planta baja se encuentra dividida en dos áreas temáticas:

1) Uniformes militares

2) Arqueología subacuática.

Además, se ha creado una sala multiusos con un auditorio para la celebración de seminarios, conferencias y reuniones, y se ha procedido al traslado de la Biblioteca Naval de la zona al museo.

\section{Imagen 1: Sala de Infantería de Marina. Museo Naval de San Fernando.}

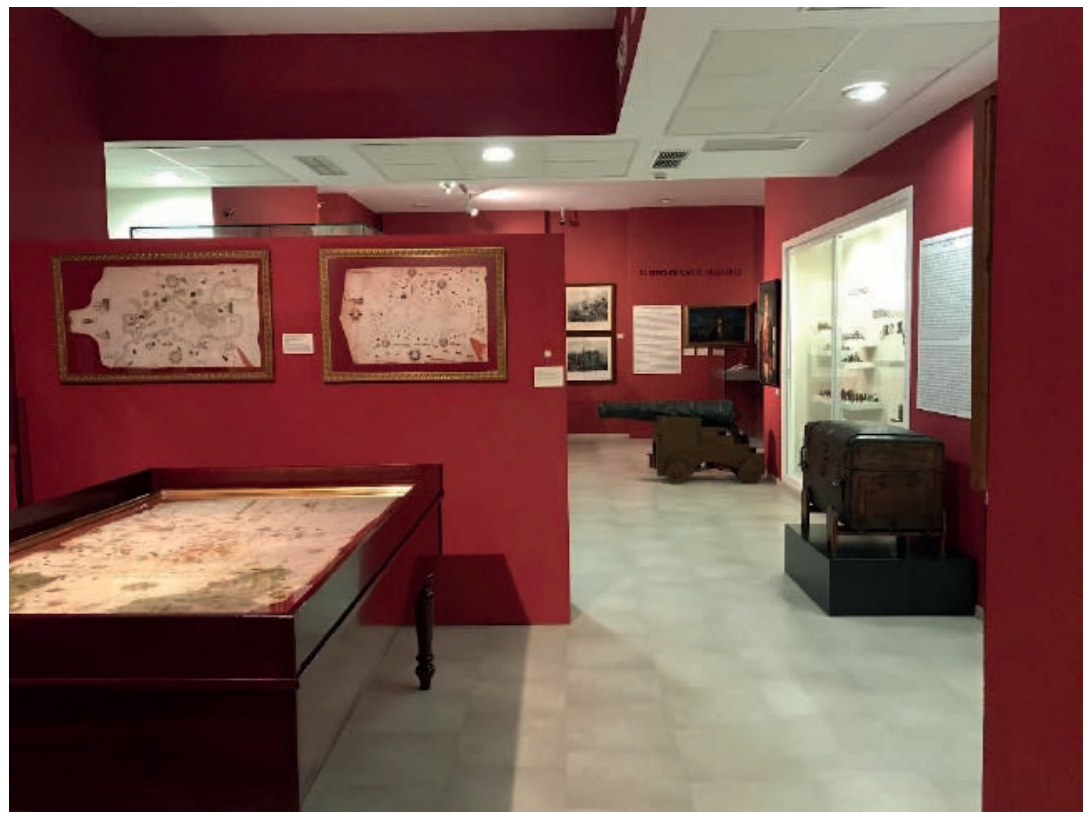

Fuente: Museo Naval de San Fernando (2018).

Otra de las estrategias llevadas a cabo, la cual puede enmarcarse dentro del campo de la Conservación Preventiva, se ha centrado en la "creación de un museo sostenible". Las actuaciones llevadas a cabo en este ámbito se concretan en los siguientes puntos:

- Conservación de los bienes culturales expuestos: cada sala cuenta con vigilantes de sala que se encargan de la seguridad de los bienes.

- Número óptimo de visitantes por sala para evitar una excesiva concentración de visitantes en sala.

- Control de la temperatura ambiental: el recinto del museo está bien climatizado y ventilado, existiendo un control diario de temperatura y humedad relativa, además de deshumidificadores y gel de sílice, colocados en el interior de las vitrinas. 
Asimismo, se ha pretendido crear un "museo más innovador", incorporando para ello las nuevas tecnologías, tal es el caso de la implantación del servicio de audioguía en los móviles personales disponible en diversos idiomas: en castellano (en dos versiones, para niños y para adultos), en inglés y en francés.

En cuanto a la estrategia de precios implantada por el museo, se ha fijado la entrada gratuita al mismo, si bien las personas que lo deseen pueden aportar de manera voluntaria 3 euros como contribución a los gastos del museo.

En el ámbito de la distribución, las actuaciones van encaminadas en la profundización de las relaciones con otras empresas emisoras de clientes, entre las que caben resaltar tanto la Universidad de Cádiz como los colegios e institutos de toda la provincia, tanto para la realización de visitas a museos, como para la celebración de reuniones y seminarios, así como la contribución en investigaciones que se lleven a cabo y que contribuyan a difundir la cultura de defensa. Asimismo, se han llegado a acuerdos con el Ayuntamiento de San Fernando para que a través de sus oficinas de turismo se promocione la visita al museo en los turistas que acudan a la localidad. Destacable, además, es la ampliación del horario de visitas del museo, lo que ha contribuido, sin lugar a dudas, a incrementar la afluencia de turistas y visitantes.

Especialmente relevantes son las diversas estrategias de comunicación puestas en marcha y entre las que cabe destacar la destinada a "promover la cultura de defensa". Con la cultura de defensa el Ministerio de Defensa contribuye a la cultura de Seguridad Nacional, atendiendo a la Ley 36/2015 de Seguridad Nacional, en la cual se establece "que el Gobierno promoverá una cultura de Seguridad Nacional que favorezca la implicación activa de la sociedad en su preservación y garantía, como requisito indispensable para el disfrute de la libertad, la justicia, el bienestar, el progreso y los derechos de los ciudadanos". Para ello, el Ministerio de Defensa lleva a cabo diversas actuaciones relacionadas con la Cultura de Defensa, entre las que cabe citar las siguientes (Ministerio de Defensa, 2016a):

- Cursos, seminarios, jornadas, mesas redondas y conferencias.

- Exposiciones de diversa naturaleza.

- Concursos de pintura, fotografía, etc.

- Conciertos de Música Militar.

- Visitas a unidades, centros y organismos militares.

- Celebración de efemérides.

- Recreaciones históricas.

Particularmente, en el Museo Naval de San Fernando se han implantado las siguientes actuaciones para contribuir a la difusión de la cultura de defensa:

- Pieza del mes. Esta actividad, promovida por el museo para dar a conocer cada mes una pieza de la colección del museo en profundidad, se ha llevado a cabo durante el año 2017.

- Participación en eventos locales. Cabe destacar la participación en el concurso de felicitaciones de Navidad, promovido en los colegios de San Fernando, cuyo objetivo es incentivar a los estudiantes a conocer los museos; la participación en "La noche en blanco" con la apertura del museo, la cual registró en 2017 la presencia de cerca de 1.200 visitantes en una sola noche; la celebración del día internacional de los museos que atrajo el día que se celebró en la edición de 2017 a 1.200 visitantes; y apertura del museo en días festivos en los que abre el comercio local, registrándose en los dos días que llevó a cabo tal actuación casi 1.000 visitantes al museo.

- Celebración de seminarios y conferencias de carácter cultural, destacándose, entre otros, el curso celebrado con la UNED, en el primer trimestre de 2018, sobre "Patrimonio Cultural de la Armada" y codirigido por la directora técnica del museo naval, Dra. Alicia Vallina Vallina.

- Tour histórico por la Marina de San Fernando, visitando varios enclaves en los que se incluyen el Real Instituto y Observatorio de la Armada, el Arsenal de la Carraca, el Museo Naval y el Panteón de Marinos Ilustres.

Otra de las estrategias de comunicación se ha centrado en la utilización del marketing online a través de la creación de una página web corporativa. La evolución del marketing online ha propiciado una mayor efectividad de las políticas de comunicación, lo que en el caso de los museos ha redundado en un mayor conocimiento de los mismos. Especialmente relevante es el papel que juegan en la actualidad las páginas web de los museos como reclamo para atraer visitantes. Las posibilidades informativas que ofrece la web de un museo son múltiples, pudiendo abarcar aspectos relevantes de su historia, horarios o catálogos de sus principales colecciones, entre otros aspectos, permitiendo, en algunos casos, realizar 
una visita virtual. Como afirma Ejarque (2005)², "el éxito de los museos y de la oferta cultural va ligado a la promoción, la flexibilidad de las tarifas y la existencia de una política comercial".

Las actuaciones de marketing online llevadas a cabo por el Museo Naval de San Fernando han utilizado varios sitios webs que incorporan información completa sobre la historia del museo, la dirección, el horario de visitas y las exposiciones con el propósito de que resulten atractivos para los visitantes potenciales y realicen la visita. Los sitios webs que integran el marketing online de este museo son:

1) El portal de Cultura de Defensa del Ministerio de Defensa.

2) La página web del Museo Naval de Madrid, sección de Museos Filiales.

Imagen 2: Página web del Museo Naval de San Fernando.

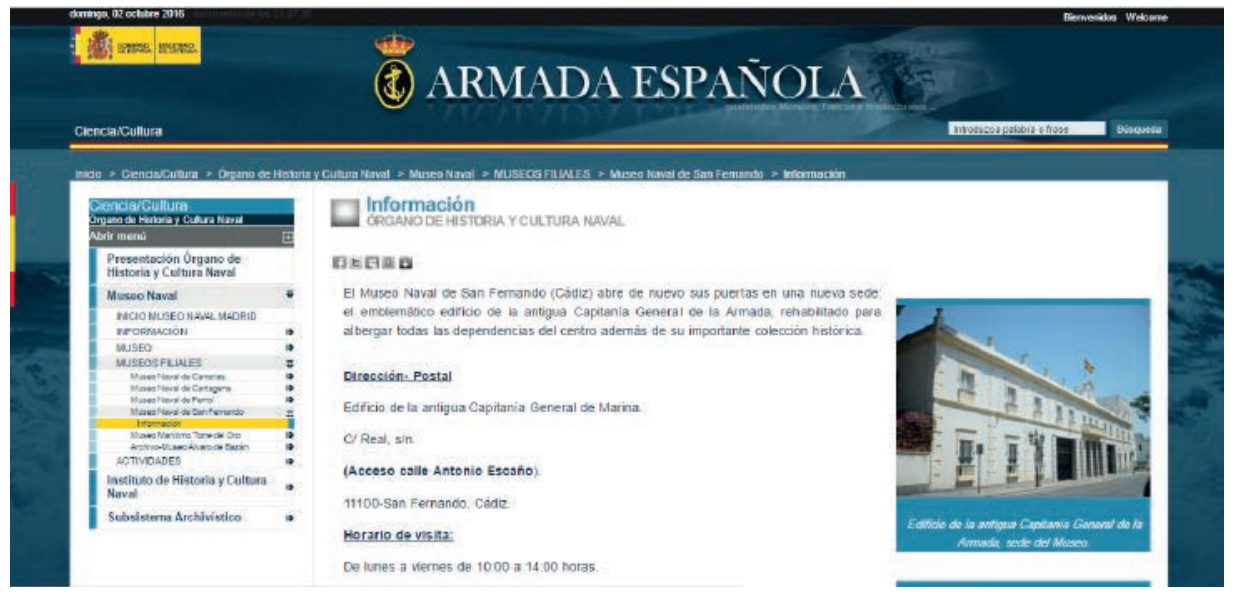

Fuente: Ministerio de Defensa (2016).

3) La página web de la Fundación Museo Naval.

Imagen 3. Portal web de la Fundación Museo Naval.

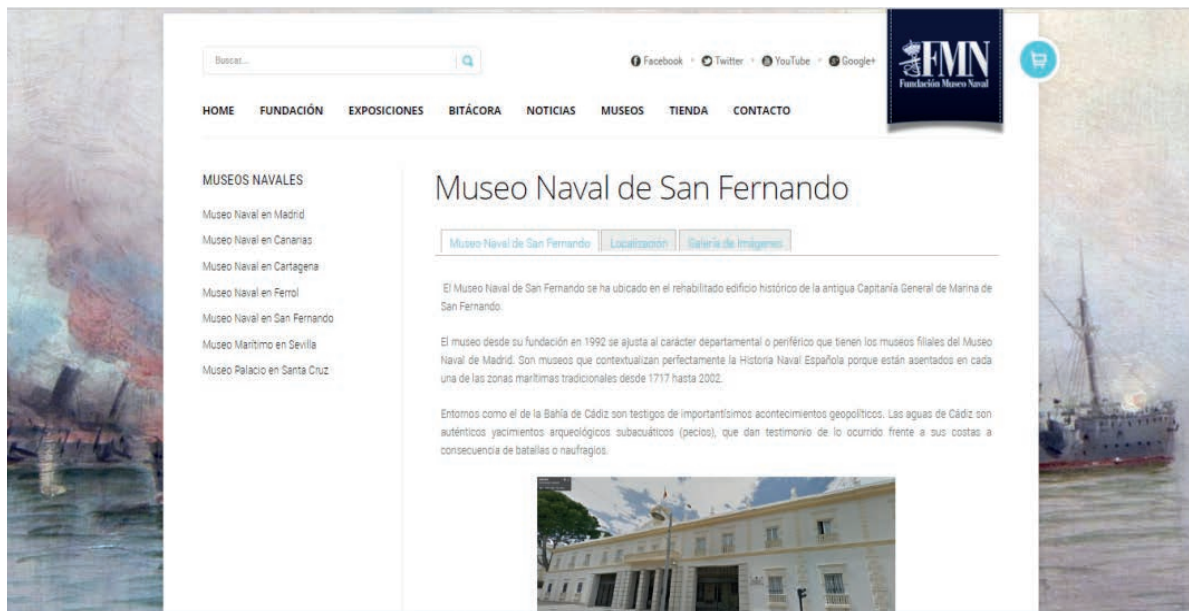

Fuente: Fundación Museo Naval (2016).

Además, es destacable la presencia del Museo en las redes sociales, concretamente en Twitter y en Facebook, tanto desde el propio museo como de la Fundación Museo Naval. 
Las diversas actuaciones llevadas a cabo en el Museo Naval de San Fernando, entre las que cabe destacar el cambio de ubicación, las mejoras considerables en las instalaciones, la incorporación de las medidas de accesibilidad, el aumento en el número de bienes culturales exhibidos, así como las diversas acciones de comunicación llevadas a cabo han propiciado el incremento en el número de visitantes al museo y con ello la difusión de los bienes que el mismo alberga.

Si bien, el número de visitantes del Museo Naval de San Fernando ha sido muy variable en su anterior ubicación y antes de la puesta en marcha de todas estas actuaciones, desde su apertura en la nueva ubicación en julio de 2016 hasta marzo de 2018 se han registrado 25.000 visitas al museo. Particularmente, en 2016 se superaron las 7.000 visitas, siendo más de 15.000 las registradas en el periodo siguiente (Gráfica 3 y Figura 3).

\section{Gráfica 3. Número de visitantes registrados en el Museo Naval de San Fernando (2006-2017).}

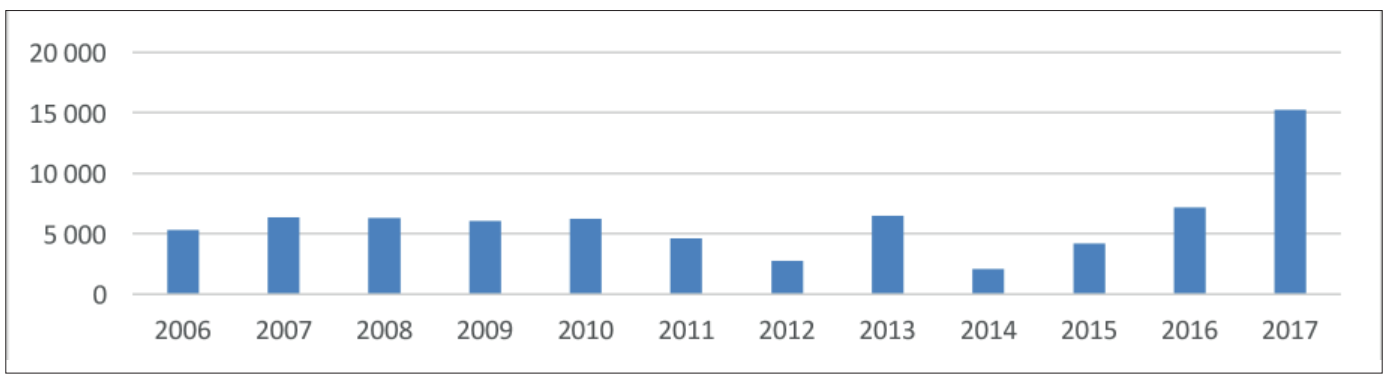

Fuente: Museo Naval de San Fernando (2018). Elaboración propia.

Tabla 3: Número de visitantes al Museo Naval de San Fernando (2006-2018)

\begin{tabular}{|l|c|l|}
\hline Año & Número de visitantes & \\
\hline 2006 & 5.298 & \\
\hline 2007 & 6.365 & \\
\hline 2008 & 6.310 & \\
\hline 2009 & 6.053 & \\
\hline 2010 & 6.206 & \\
\hline 2011 & 4.599 & Cerrado de agosto de 2012 a febrero de 2013 \\
\hline 2012 & 2.731 & \\
\hline 2013 & 6.467 & Cerrado desde noviembre por inicio de los trabajos de cambio de sede \\
\hline 2014 & 2.048 & Apertura parcial del museo \\
\hline 2015 & 4.138 & Del 8 de julio al 31 de diciembre. \\
\hline 2016 & 7.127 & \\
\hline 2017 & 15.249 & \\
\hline
\end{tabular}

Fuente: Museo Naval de San Fernando (2018). Elaboración propia.

La gestión realizada en el museo, no sólo se ha visto reflejada en un aumento del número de visitantes, sino también en un mejor posicionamiento del mismo, convirtiendo algunas de las debilidades existentes antes de la puesta en marcha del plan de marketing, tales como la ubicación, la apertura a la ciudadanía, los accesos (horarios), la accesibilidad, la formación del personal, la conservación y sostenibilidad, en fortalezas, las cuales han contribuido todas ellas a mejorar la posición competitiva del museo, así como su atractivo, lo que ha redundado en la dinamización turística de la localidad. 


\section{Conclusiones}

En los últimos años, se ha impulsado desde el Ministerio de Defensa del Gobierno de España la promoción y puesta en valor de su patrimonio cultural lo que ha contribuido a dinamizar el sector turístico del país. Entre las diversas actuaciones, cabe destacar el acuerdo de colaboración firmado en julio de 2013 por este Ministerio y el Ministerio de Industria, Energía y Turismo, a través de Turespaña, para promocionar el patrimonio histórico artístico, así como otras actividades culturales relacionadas con la Defensa. Este acuerdo de colaboración partió de un doble propósito, poder mostrar el patrimonio cultural de defensa (museos, castillos, palacios o fortalezas) a un mayor número de personas, por un lado, y contribuir a impulsar el sector turístico en España, por otro lado. Las actuaciones implantadas a la luz de este acuerdo, unidas a las llevadas desde la Fundación Museo Naval (Ministerio de Defensa) al objeto de promover, difundir y proteger el patrimonio de la Armada y la historia naval, han contribuido a la puesta en valor del patrimonio cultural que gestiona el Ministerio de Defensa.

De esta manera, el amplio patrimonio cultural militar español, integrado por archivos, bibliotecas, museos y edificios emblemáticos de gran valor, se ha convertido en un referente en las ciudades donde se encuentran ubicados, gracias a las actuaciones de comunicación y difusión llevadas a cabo, constituyéndose en atractivos turístico-culturales de gran trascendencia para estas localidades. Tal es el caso Museo Naval en la ciudad de San Fernando (Cádiz), el cual se ha constituido en eje fundamental para el desarrollo del turismo cultural en esta localidad.

Partiendo del análisis situacional del entorno, en el que queda reflejado el auge del turismo cultural en todo el mundo, y al objeto de aprovechar tal oportunidad, se han delimitado como objetivos fundamentales acercar el museo a la ciudadanía, incrementando el número de visitantes a sus instalaciones, así como aumentar la notoriedad del museo; tratando de lograr un posicionamiento definido "ser un museo actual y especializado en el ámbito naval con un mayor reconocimiento en el mercado turístico" y "difundir la cultura de defensa".

Las estrategias y actuaciones llevadas a cabo para la consecución de tales objetivos se han centrado en lograr una mayor apertura del museo a toda la ciudadanía, mejorar los canales de distribución y sobre todo impulsar la promoción del museo a través de las estrategias de comunicación, todo lo cual ha llevado a un notable incremento de los visitantes y turistas a los museos, contribuyendo a difundir los recursos que integran el patrimonio cultural que gestiona este organismo. Tanto es así que el Museo Naval es considerado en la actualidad uno de los principales atractivos culturales y turísticos no sólo de la localidad sino de toda la provincia.

Todo lo cual pone de manifiesto la idoneidad del diseño y puesta en práctica de estrategias de marketing orientadas a lograr un mejor posicionamiento estratégico de los recursos culturales y turísticos, más aún en destinos turísticos como España, por cuanto ocupa una posición privilegiada tanto en el ámbito turístico, siendo la segunda potencia mundial en lo que al número de turistas internacionales se refiere, como en el ámbito cultural, siendo uno de los países con mayor riqueza patrimonial en todo el mundo.

\section{Agradecimientos}

la realización de este trabajo ha sido posible gracias a la colaboración del Subdelegado del Ministerio de Defensa en la provincia de Cádiz, Coronel D. Joaquín Tomás González Fernández, del director del Museo Naval de San Fernando durante la realización de la investigación, Capitán de Navío D. Vicente Pablo Ortells Polo, así como de la directora técnica del museo, Dra. Alicia Vallina Vallina.

\section{Bibliografía}

Alejandre, F.

2017. "La Cultura de Seguridad y Defensa: un imperativo en una sociedad avanzada". Revista Española de Defensa. Junio.

Biblioteca Virtual de Defensa

2016. Obras destacadas. Disponible en:http://bibliotecavirtualdefensa.es/BVMDefensa/i18n/estaticos/ contenido.cmd?pagina=estaticos/presentacion. Consultado en: octubre de 2017.

De Leste, T.

2018. "La Armada y el Patrimonio Cultural Naval". Disponible en: http://www.mecd.gob.es/fragatamercedes/ $\mathrm{dms} /$ museos/fragatamercedes/patrimonio-cultural-subacuatico/armada-patrimonio-cultural-naval. pdf. Consultado en: Junio de 2018. 
Exceltur

2016. Informe de perspectivas turísticas. Valoración turística empresarial de 2015 y perspectivas para 2016. N ${ }^{\circ}$ 55. Enero de 2016. Balance 2015.

Fernández, M. y Barbeito, R.

2005. "El papel de los museos militares en el fomento de una cultura de defensa democrática". Barataria. Revista Castellano-Manchega de Ciencias Sociales. Nº 7: 63-69.

Fernández, G. y Ramos, A.G.

2005. "Patrimonio industrial y rutas turísticas culturales: algunas propuestas para Argentina". Cuadernos de Turismo. $\mathrm{N}^{\mathrm{o}}$ 15: 97-112. Murcia.

Fundación Museo Naval

2016. Museos. Disponible en: http://fundacionmuseonaval.com/. Consultado en: octubre de 2016.

González-Pola, P.

2018. La aportación de la museología a la cultura de defensa en España. Ponencia. Real Academia de

Doctores de España. Disponible en: http://www.radoctores.es.

Gummenson, E.

1991. Qualitative Methods in Management Research. Newbury Park, CA, Sage Publications.

Kolter, K. y Keller, K.

2016. Dirección de Marketing. Decimoquinta edición. Pearson. México.

Kotler, N. y Kotler, P.

2008. Estrategias y marketing de museos. $2^{\text {a }}$ Edición. Ariel. Barcelona.

Lavado, $\mathrm{P}$.

2002. "Museos sin barreras y sin fronteras: accesibilidad, comunicabilidad e integración". Boletín de la Asociación Asturiana de Bibliotecarios, Archiveros, Documentalistas y Museólogos (AABADOM) Enero-Junio.

Ley 16/1985, de 25 de junio, del Patrimonio Histórico Español.

Ley 51/2003, de 2 de diciembre, de igualdad de oportunidades, no discriminación y accesibilidad universal de las personas con discapacidad.

Martos, M.

2016. Herramientas para la gestión turística del patrimonio cultural. Ediciones Trea, S.L. Gijón, Asturias. Milio, I. y Cabo, M.

2000. Comercialización de productos y servicios turísticos. Paraninfo. Madrid: Thomson Learning. Madrid. Ministerio de Defensa

2011. Guía de Museos Militares Españoles. Disponible en: directoriomuseos.mcu.es/dirmuseos. Consultado en: octubre de 2017.

Ministerio de Defensa

2016a. Cultura de Defensa. Disponible en: http://www.portalcultura.mde.es/comun/culturaDefensa. html. Consultado en: septiembre de 2017.

Ministerio de Defensa

2016b. Estadística de Centros, Instalaciones y Actividades Culturales y Deportivas. Año 2015. Secretaría General Técnica. Unidad de Estadística del Órgano Central. Julio 2016. Disponible en: http:// publicaciones.defensa.gob.es. Consultado en: septiembre de 2017.

Ministerio de Defensa

2018. "La Cultura de Defensa". Disponible en: www.portalcultura.mde.es/comun/culturaDefensa.html. Consultado en: junio de 2018.

Ministerio de Educación, Cultura y Deporte

2016a. Encuesta de hábitos y prácticas culturales en España. Disponible en: https://www.mecd.gob.es/ servicios-al-ciudadano/estadisticas/cultura/mc/ehc/portada.html. Consultado en: octubre de 2017.

Ministerio de Educación, Cultura y Deporte

2016b. Estadísticas de museos y colecciones museográficas. Disponible en: http://www.mecd.gob.es/ servicios-al-ciudadano-mecd/estadisticas/portada.html;jsessionid=8CFB04ED9399038E5DB33410 B1E3DDD1. Consultado en: octubre de 2017.

Orden DEF/2532/2015, de 18 de noviembre, por la que se crea la Red de Museos de Defensa y se definen los procedimientos para la gestión de los bienes muebles del Patrimonio Histórico Español adscritos al Ministerio de Defensa.

Organización Mundial del Turismo (O.M.T.): Sustainable Development of Tourism: mission Statement. Disponible en: http://goo.gl/Rf30Nv. Consultado en: septiembre de 2016. 
Periáñez. I. y Quintana, M.A.

2009. "Caso práctico: la planificación estratégica del museo Guggenheim Bilbao desde una perspectiva de marketing". Cuadernos de Gestión, Vol. 9 (1): 99-122.

Real Decreto 1414/2006, de 1 de diciembre, por el que se determina la consideración de persona con discapacidad a los efectos de la Ley 51/2003, de 2 de diciembre, de Igualdad de oportunidades, no discriminación y accesibilidad universal de las personas con discapacidad.

Real Decreto 1305/2009, de 31 de julio, por la que se crea la Red de Museos de España.

Real Patronato de Discapacidad (2004): Curso de turismo accesible. Ministerio de Trabajo y Asuntos Sociales. $2^{\text {a }}$ reimpresión.

Reglamento 620/1987, de 10 de abril, por el que se aprueba el Reglamento de Museos de Titularidad Estatal y del Sistema Español de Museos.

Troitiño, M.A.

1998. Turismo y desarrollo sostenible en ciudades históricas. Ería, 57: 211-227.

UNESCO

2014. Gestión del Patrimonio Mundial Cultural. París. Francia.

Velasco, M.

2009. Gestión turística del patrimonio cultural: enfoques para un desarrollo sostenible del turismo cultural. Cuadernos de turismo, $\mathrm{n}^{\circ}$ 23: 237-253. Universidad de Murcia.

Villareal, O. y Landeta, J.

2010. "El estudio de casos como metodología de investigación científica en dirección y economía de la empresa. Una aplicación a la internacionalización". Investigaciones Europeas de Dirección y Economía de la Empresa, vol. 16 (4): 31-52.

Yin, R.K.

2009. Case study research: design and methods. Sage Publications. Thousand Oaks, CA, United States.

\section{Notas}

1 Desarrollada por el Ministerio de Educación, Cultura y Deporte, con la colaboración del Ministerio de Defensa, de Patrimonio Nacional y de las Comunidades y Ciudades Autónomas.

2 Ejarque, J. (2005). Destinos turísticos de éxito. Diseño, creación, gestión y marketing. Madrid. Pirámide. Tomado de Martos (2016). 